\title{
Die XY-Gesellschaft
}

Erhard Taverna
Bereits 1741 kommentierte der Mediziner und Feldprediger Johann Peter Süssmilch das bekannte Geburtsverhältnis von 100 Mädchen zu 105 Knaben. Heute zählt er zu den Pionieren der Bevölkerungsstatistik, und seine Beobachtung gilt für alle Kulturen bis in die Neuzeit. 250 Jahre später beschrieb der französische Demograph Christophe Guilmoto als Erster eine alarmierende Abweichung von dieser Regel in Staaten wie Indien und China.

\section{Die Fakten}

Der grösste Geburtenrückgang in den vergangenen fünfzig Jahren fand in Asien statt. Die durchschnittliche Kinderzahl von 5,7 in den späten 1960ern sank bis 2006 auf 2,3 Kinder pro Frau. In Südkorea, Japan, Taiwan, Singapur, Hongkong und Macau haben die meisten Eltern nur ein Kind. Um dennoch einen Sohn zu bekommen, werden weibliche Feten so lange abgetrieben, bis der männliche Nachfolger gesichert ist. Die Folgen dieses Jahrzehnte andauernden, selektiven Fetozids sind heute massive Verzerrungen der

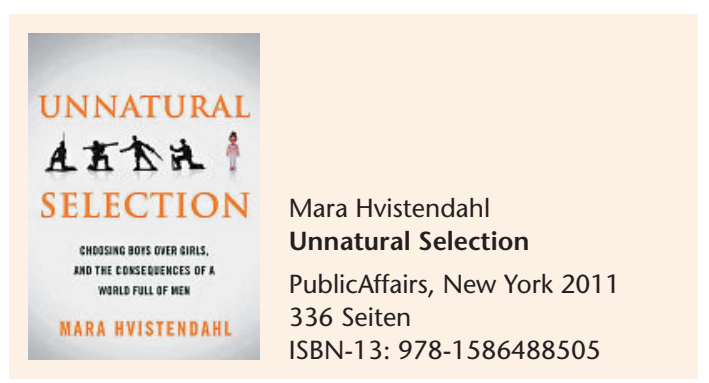

trennbar miteinander verknüpft. China übernahm in den 1970ern diese westlichen Konzepte und forcierte eine gewaltsame Ein-Kind-Politik, unter anderem mit mobilen Abtreibungskliniken auf dem Lande. Indien führte 1975 in öffentlichen Spitälern die Amniozentese ein und startete gleichzeitig eine Kampagne, in der innerhalb eines Jahres 6,2 Millionen Männer mehr oder weniger freiwillig vasektomiert wurden. Alle diese Massnahmen finanzierte die Weltbank mit grossen Geldsummen, unterstützt von zahlreichen

\section{Je gebildeter die Mütter sind, desto entschiedener fällt die Wahl zugunsten eines Jungen aus. Diese Frauen wissen sehr wohl, was es heisst, in ihrem Land eine Frau zu sein.}

Geschlechtsverhältnisse. Trotz Verboten kommen in China 121 männliche auf 100 weibliche Neugeborene, in Indien 112 auf 100 und in einzelnen Städten und Provinzen bis 163 zu 100. Heute fehlen der Bevölkerung rund 163 Millionen Frauen.

Wie es dazu kam und welche Probleme daraus entstehen, beschreibt die amerikanische Journalistin Mara Hvistendahl in ihrem Buch Unnatural Selection Choosing boys over girls, and the consequences of a world full of men. Die mehrfach ausgezeichnete Chinakennerin beschreibt minutiös den Werdegang einer weitgehend verdrängten Katastrophe, zu der westliche Erfindungen und der Kalte Krieg wesentlich beigetragen haben. Die Angst vor der «gelben Gefahr» wuchs mit Maos Erfolgen in China, was die USA dazu bewog, Japan und Südkorea als Versuchslabors für eine staatliche Familienpolitik mittels intensiver Abtreibungskampagnen zu gewinnen.

Abnehmende Geburtsraten, Wirtschaftswachstum und selektive Abtreibungen sind seither un- westlichen Organisationen, wobei auch direkte Wirtschaftshilfe von der jeweiligen Familienplanung abhing.

In den 1940er Jahren wurden die Grundlagen der pränatalen Geschlechtsbestimmung entwickelt. Der Genetiker Murray L. Barr wurde für seine Entdeckung des Sex Chromatins für den Nobelpreis nominiert, 1968 wurden mit seiner Methode die Teilnehmer der Olympischen Spiele kontrolliert. Die spätere Massenproduktion von Ultraschallgeräten ermöglichte sehr schnell auch in abgelegenen Landesteilen eine sichere und billige Methode der Geschlechtsbestimmung. Mara Hvistendahl und andere haben nachgewiesen, dass nicht nur arme, ungebildete und traditionsverhaftete Gesellschaftsschichten für das Ungleichgewicht verantwortlich sind. Es sind die reicheren, urbanen Eltern, die sich medizinische Untersuchungen und Abtreibungen leisten können. Wohlstand und Bildung führen in der aufstrebenden Mittelklasse zu scheinbar paradoxen Nebenwirkungen. Je 
gebildeter die Mütter sind, desto entschiedener fällt die Wahl zugunsten eines Jungen aus. Diese Frauen wissen sehr wohl, was es heisst, in ihrem Land eine Frau zu sein.

Der Männerüberfluss geht wieder zulasten der Frauen. Auch das kann Hvistendahl nachweisen. Die

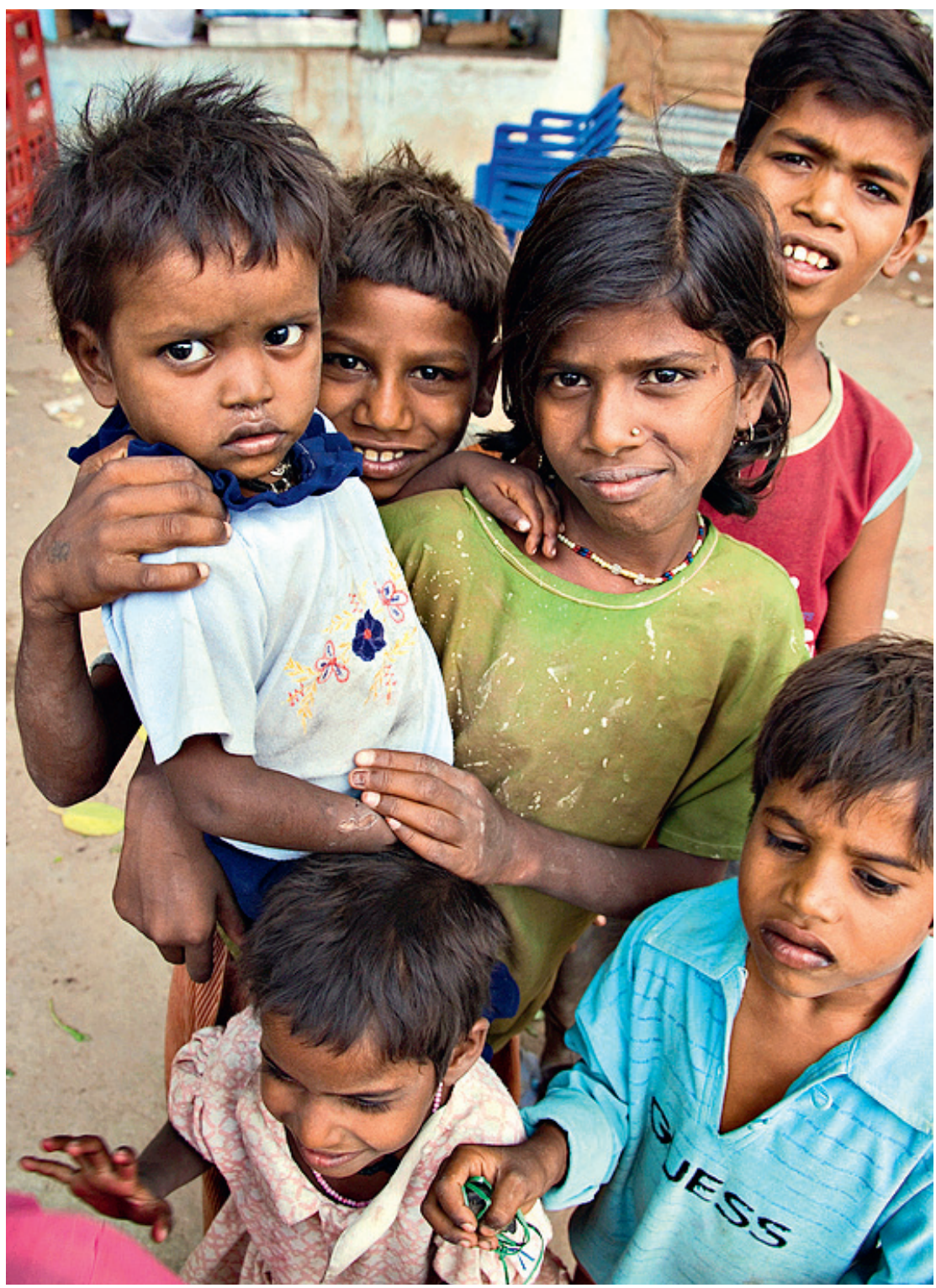

Unnatürliche Selektion: In gewissen Städten und Regionen Indiens kommen 163 männliche Neugeborene auf 100 weibliche.
Mordraten nehmen dort zu, wo das grösste Missverhältnis besteht. Entführungen, Prostitution und Menschenhandel sind an der Tagesordnung. Dass diese unstabilen Gesellschaften für kriegerische Konflikte anfälliger sind, weiss man spätestens seit dem Raub der Sabinerinnen.

\section{Die Diskussion}

Abtreibungsgegner in den USA benützen die Studien, um restriktivere Gesetze durchzubringen. Dass lange Zeit konservative Republikaner die Abtreibung propagierten, verschweigen sie. Damals ging es darum, die Zahl möglicher Kommunisten im Ausland zu verringern, zu Hause sollte das Patriarchat intakt bleiben. Die Recherchen der Autorin lassen niemanden ungeschoren. Alle politischen Parteien, Wissenschaftler, Ärzte, die medizinische Industrie, NGOs (Nichtregierungsorganisationen), Entwicklungshelfer und die UNO haben zu dieser Entwicklung beigetragen. Inzwischen hat diese Praxis auch in Ländern Osteuropas, in Albanien, Georgien und Aserbeidschan zu ähnlichen demografischen Verzerrungen geführt.

Mara Hvistendahl kritisiert auch die UNFPA (United Nations Population Fund), eine Behörde, die für die Rechte von Frauen, Männern und Kindern einsteht. Die millionenfach praktizierte Abtreibung weiblicher Feten ist dort immer noch kein offizielles Thema. Neue Techniken, wie die Präimplantationsdiagnostik PID oder die Trennung in X- und Y-Spermien vor der Insemination werden reichen Kunden in vielen Ländern, darunter auch China, Indien und die USA, ausschliesslich zur Geschlechtsdifferenzierung angeboten. Dabei ist abzusehen, dass die Nachfrage mit sinkenden Preisen zunehmen wird.

Der Autorin geht es nicht primär um die Abtreibung weiblicher Feten oder um andere Methoden, die den weiblichen Nachwuchs aussortieren. Der eigentliche Skandal liegt tiefer. Es geht ihr um Frauen, die ihre eigenen Töchter verleugnen müssen, um in einer Männergesellschaft besser akzeptiert zu sein. Vielleicht werden in naher Zukunft «elegantere» Methoden die Ära der Abtreibungen beenden. Das Buch endet in einer US-Privatklinik mit langen Wartelisten von Eltern, die von einem Baby nach Mass träumen, ein Trend, den die Genforschung unumkehrbar vorantreibt. Vielleicht endet der Geschlechterkampf im Brave New World des 21. Jahrhunderts. 